\title{
Effect of D.C. Voltages Using HCl for the Synthesis and Characterization of Polyaniline
}

\author{
G. Umadevi, ${ }^{a, *}$ V. Ponnusamy, ${ }^{a}$ M. Paramsivam ${ }^{b}$ and A.Elango ${ }^{c}$ \\ ${ }^{a}$ Sri Ramakrishna Mission Vidhyalaya College of Arts and Science, Coimbatore, India \\ ${ }^{b}$ Functional Material Division, CECRI, Karaikudi, India \\ ${ }^{c}$ Mechanical Engg., A.C. College of Engineering and Technology, Karaikudi, India
}

Received 15 January 2008; accepted 10 November 2008

\begin{abstract}
This study is related to the electrochemical polymerisation of aniline in the presence of hydrochloric acid at DC voltages from $1.1 \mathrm{~V}$ to $2.1 \mathrm{~V}$ with platinum, stainless steel electrodes of uniform cross section. $1 \mathrm{M}$ of acid and $0.1 \mathrm{M}$ of monomer are taken. Efforts are concentrated on the importance of polyaniline deposited on the working electrode and the collection of pure samples out of it from forty trials each. Each trial runs for one hour. Double distilled water is used for the filtering of polyaniline. Due to the presence of mono basic acid, the FTIR peaks are well defined and their presence indicates the definite vibrational modes of the elements. The acid affects the polymerization of aniline and the results are in reasonable agreement with earlier reports. At $1.7 \mathrm{~V}$ the conductivity is well exhibited by $\mathrm{HCl}$ doped PANI. It is found that the applied DC voltage plays a role on the synthesis of polyaniline using $\mathrm{HCl}$.
\end{abstract}

Keywords: conducting polymers, polyaniline, PANI, electrochemical polymerization, monobasic acid.

\section{Introduction}

During recent years, considerable interest has been concentrated on polymerization of aniline and on the properties of polyaniline as a conducting organic polymer [1]. The supporting electrolyte affects the electrochemical polymerization of aniline and the properties of polyaniline.

Electrochemical polymerization uses an initial electrochemical step, generally oxidation via an applied potential to generate the radical ion, which then initiates the polymerization. 3 electrode / 2 electrode (working, counter) mode may be used. In this work one platinum plate and one stainless steel plate are used in $\mathrm{HCl}$.

\footnotetext{
* Corresponding author. E-mail address: amukaraish@yahoo.co.in
} 
Electrochemical polymerization became a widely used procedure for quick generation of conducting polymers. Electrically conducting polymers are a novel class of synthetic metals that continue the chemical and mechanical properties of polymers with the electric properties of metals and semiconductors. Polyaniline is a conducting polymer, which can be easily synthesized by both the chemical and electrochemical methods. Polyaniline prepared by the electrochemical method is a stable conducting polymer $[2,3]$. Polyaniline is one of the most intensively conducting polymers studied during the last decade. It is highly conducting, easy to synthesize both chemically as a powder, and electrochemically as a powder and as a film.

This work aims at the detailed study of the influence of acid in the properties of the resulting PANI $[4,5,6,7]$. Polyaniline finds a wide range of applications due to its redox properties. The effects of acid at different voltages are studied. The results are supplemented by FTIR.

\section{Experimental}

\section{Monomer}

Aniline GR MERCK monomer is distilled under reduced pressure and stored in dark below $4{ }^{\circ} \mathrm{C}$.

\section{Solutions}

The aggressive solutions are made of AR grade $\mathrm{HCl} .1 \mathrm{M}$ of acid is prepared using double distilled water.

\section{Electrodes}

\section{Working electrode}

Design of working electrode is diverse. An essential feature is that the electrode should not react chemically with the solvent or solution components. It is desirable to have an even current and potential distribution, so that all the points on the working electrode surface are geometrically equivalent with respect to the secondary electrode.

\section{Reference electrode}

The role of the reference electrode (RE) is to provide a fixed potential which does not vary during the experiments. The $\mathrm{RE}$ serves dual purposes of providing a thermodynamic reference and also isolating working electrode from the system. The working electrode and the reference electrode used are given in the Table 1.

Table 1. Electrodes.

\begin{tabular}{|c|c|c|}
\hline Acid & Working electrode & Reference electrode \\
\hline $\mathrm{HCl}$ & Platinum & Stainless steel \\
\hline
\end{tabular}

\section{Synthesis of polyaniline}

$1 \mathrm{M}$ of hydrochloric acid (98\%) AR grade is taken. $0.1 \mathrm{M}$ of aniline is added drop by drop into it. The mixture is stirred by a magnetic stirrer ( $2 \mathrm{MCH}-\mathrm{Remi}$ equipments) for about an hour. The solution obtained is taken in the $250 \mathrm{~mL}$ beaker. Deionised water is used for the preparation of the solution. A DC regulated power supply (SPAARK TEX) with an accuracy of 0.001 A current is used for supplying voltages from 1.1 to $2.1 \mathrm{~V}$. Two electrodes are immersed parallel to each other in the solution. The electrodes are 
connected to a DC power supply using suitable connecting wires. As soon as the circuit is closed with 1.1 Volt, the electrochemical polymerization of polyaniline takes place and polyaniline starts to deposit on the electrode. The polyaniline deposited is collected. The experiment is carried out with different DC voltages (1.1 to $2.1 \mathrm{~V})$. 40 trials are taken for each voltage. A vacuum pump (Prabivac) is used for removing moisture for 1 hour. And finally the product is dried in an oven at $40{ }^{\circ} \mathrm{C}$ for 12 hours (Tempo Instruments).

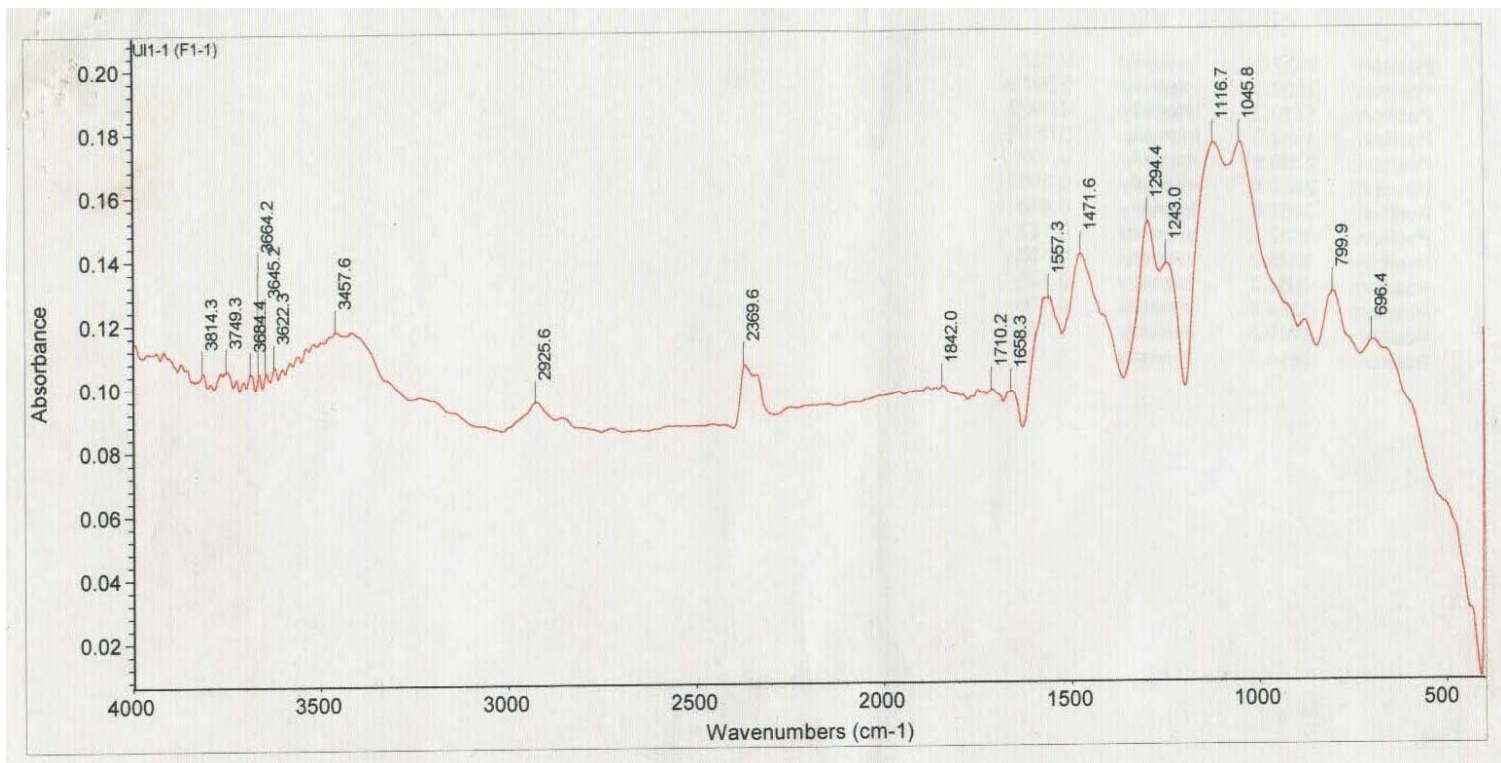

Figure 1. FTIR of polyaniline at $1.1 \mathrm{~V}$ - platinum electrode.

\section{Fourier transform infra-red spectroscopy}

A small quantity of the dried powder obtained is as such subjected to FTIR analysis. The spectra are recorded by using an Elmer infra-red spectroscope. The FTIR spectra recorded for DC voltages, $1.1 \mathrm{~V}, 1.3 \mathrm{~V}, 1.5 \mathrm{~V}, 1.7 \mathrm{~V}, 1.9 \mathrm{~V}$ and $2.1 \mathrm{~V}$, are shown in Figs. 1, 2, 3, 4, 5 and 6, respectively.

\section{Results and discussion \\ FTIR study on $\mathrm{HCl}$ doped polyaniline}

The various vibrational modes of polyaniline prepared using $\mathrm{HCl}$ at $1.1 \mathrm{~V}, 1.3 \mathrm{~V}, 1.5 \mathrm{~V}$, $1.7 \mathrm{~V}, 1.9 \mathrm{~V}$ and $2.1 \mathrm{~V}$, are given in Table 2. It is observed that peaks at 1400-1600, 700 $\mathrm{cm}^{-1}$ are the characteristic of the various vibration modes of the $\mathrm{C}-\mathrm{H}$ and $\mathrm{C}=\mathrm{C}$ bonds of aromatic nuclei $[8,9]$. The band near $3400 \mathrm{~cm}^{-1}$ corresponds to the stretching of $\mathrm{N}-\mathrm{H}$ bands. The band at $1300 \mathrm{~cm}^{-1}$ is assigned to the stretching of $\mathrm{C}-\mathrm{N}$ bonds of aromatic amines. The strong band at $1130 \mathrm{~cm}^{-1}$ (Table 3) is considered to be a measure of the degree of electron delocalization as in Fig. 4 and thus it is a characteristic peak of PANI conductivity [10]. 
Table 2. FTIR spectra of polyaniline prepared using $\mathrm{HCl}$.

\begin{tabular}{|c|c|c|c|}
\hline $\begin{array}{c}\mathrm{DC} \\
\text { voltage }\end{array}$ & $\mathrm{HCl}$ & $\begin{array}{c}\text { DC } \\
\text { voltage }\end{array}$ & $\mathrm{HCl}$ \\
\hline $1.1 \mathrm{~V}$ & $\begin{array}{l}\text { 3664.2 -N-H stretching } \\
3457.6 \text {-N-H primary carbon stretching } \\
\text { 1557.3 -C=C stretching vibration } \\
\text { 799.9 -N- H out of plane bending } \\
696.4 \text {-C-H out of plane bending }\end{array}$ & $1.7 \mathrm{~V}$ & $\begin{array}{l}3423.0-\mathrm{N}-\mathrm{H} \text { stretching } \\
2919.9 \text { - C-H stretching } \\
1297.7-\mathrm{C}-\mathrm{N} \text { stretching vibration } \\
1128.7 \text { - C-H in plane on } 1,4 \text { ring aromatic } \\
\text { amines } \\
\text { *PANI conductivity }\end{array}$ \\
\hline $1.3 \mathrm{~V}$ & $\begin{array}{l}\text { 3664.4 - N-H stretching } \\
3420.1-\mathrm{N}-\mathrm{H} \text { primary carbon stretching } \\
\text { 1560.3 - C=C stretching vibration } \\
\text { 1477.2 - C-H deformation in } \mathrm{CH}_{2} \text { groups } \\
\text { 805.3 - N-H out of plane bending (rocking) } \\
693.8-\mathrm{C}-\mathrm{H} \text { out of plane bending }\end{array}$ & $1.9 \mathrm{~V}$ & $\begin{array}{l}3434.7-\mathrm{N}-\mathrm{H} \text { primary carbon stretching } \\
1569.8-\mathrm{C}=\mathrm{C} \text { stretching vibration } \\
801.1-\mathrm{N}-\mathrm{H} \text { out of plane bending (rocking) } \\
671.2-\mathrm{C}-\mathrm{H} \text { out of plane bending }\end{array}$ \\
\hline $1.5 \mathrm{~V}$ & $\begin{array}{l}3664.5-\mathrm{N}-\mathrm{H} \text { stretching } \\
3436.4-\mathrm{N}-\mathrm{H} \text { primary carbon stretching } \\
1559-\mathrm{C}=\mathrm{C} \text { stretching vibration } \\
\text { 799.0 }-\mathrm{N}-\mathrm{H} \text { out of plane bending (rocking) } \\
681.0-\mathrm{C}-\mathrm{H} \text { out of plane bending }\end{array}$ & $2.1 \mathrm{~V}$ & $\begin{array}{l}\text { 3457.2 }-\mathrm{N}-\mathrm{H} \text { primary carbon stretching } \\
1569.2-\mathrm{C}=\mathrm{C} \text { stretching vibration } \\
1126.1-\mathrm{A} \text { symmetric C-C- N stretching } \\
\text { vibration } \\
805.4-\mathrm{N}-\mathrm{H} \text { out of plane bending } \\
675.6-\mathrm{C}-\mathrm{H} \text { out of plane bending }\end{array}$ \\
\hline
\end{tabular}

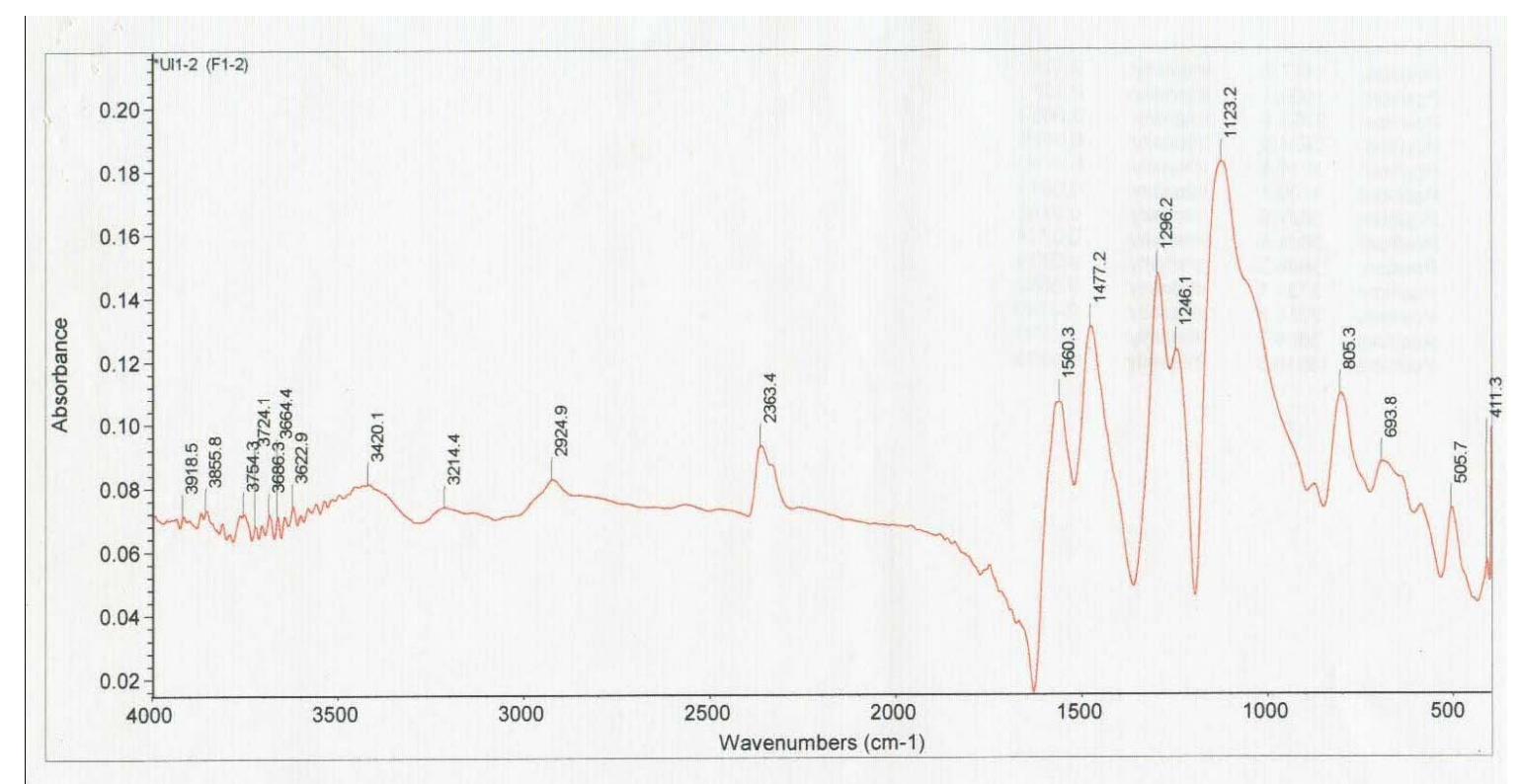

Figure 2. FTIR of polyaniline at $1.3 \mathrm{~V}$ - platinum electrode.

From FTIR spectra of polyaniline prepared in the presence of monobasic acid $(\mathrm{HCl})$, the peaks at $3443 \mathrm{~cm}^{-1}$ assigned to N-H stretching vibration of PANI prepared using $\mathrm{HCl}$ are observed. The peaks at $2925 \mathrm{~cm}^{-1}, 1485 \mathrm{~cm}^{-1}, 1247 \mathrm{~cm}^{-1}$ are assigned to the vibrations associated with the $\mathrm{N}-\mathrm{H}$ stretching, benzenoid ring, the $\mathrm{C}-\mathrm{N}$ stretching vibration of aromatic amine of $\mathrm{HCl}$ doped polyaniline (at $1.3 \mathrm{~V}, 2.1 \mathrm{~V}, 1.5 \mathrm{~V}$ ). C-H vibrations (at $2925 \mathrm{~cm}^{-1}$ ) occur in this case for $1.3 \mathrm{~V}$. Benzenoid (1485) structure is 
revealed at $2.1 \mathrm{~V}$ for $\mathrm{HCl}$. C-N stretching vibration of 1247 occurs at $1.5 \mathrm{~V}$. Benzene ring formation at $805 \mathrm{~cm}^{-1}$ occurs at $1.3 \mathrm{~V}$. (Figures 1,2, 3,5,6).

Table 3. PANI conductivity.

\begin{tabular}{|l|c|}
\hline \multicolumn{1}{|c|}{ Wave number } & $\mathrm{HCl}$ \\
\hline $1130 \mathrm{~cm}^{-1}$ characteristic peak of PANI conductivity & $1.7 \mathrm{~V}$ \\
\hline Quinoid structure & $1.9 \mathrm{~V}$ \\
\hline
\end{tabular}

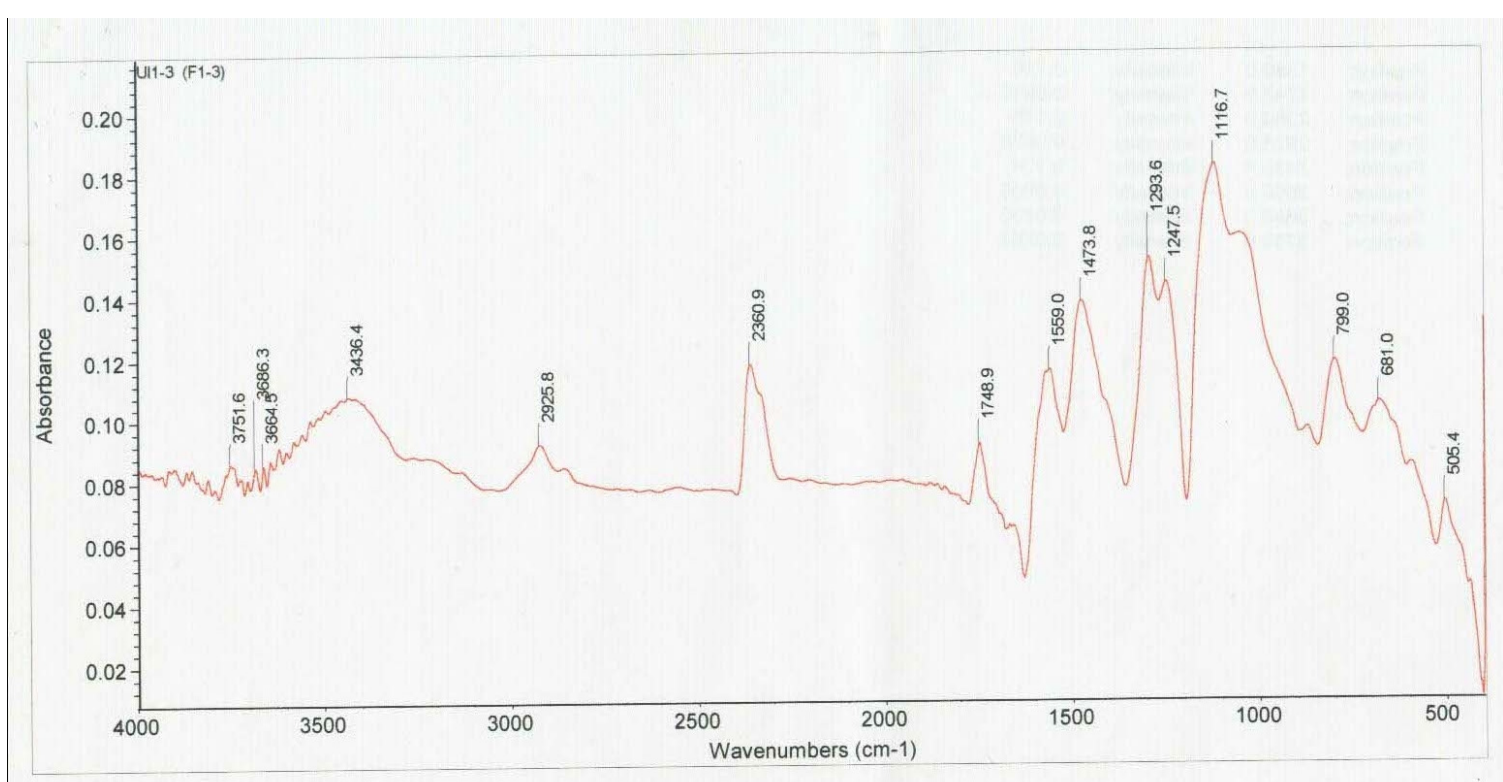

Figure 3. FTIR of polyaniline at $1.5 \mathrm{~V}$ - platinum electrode.

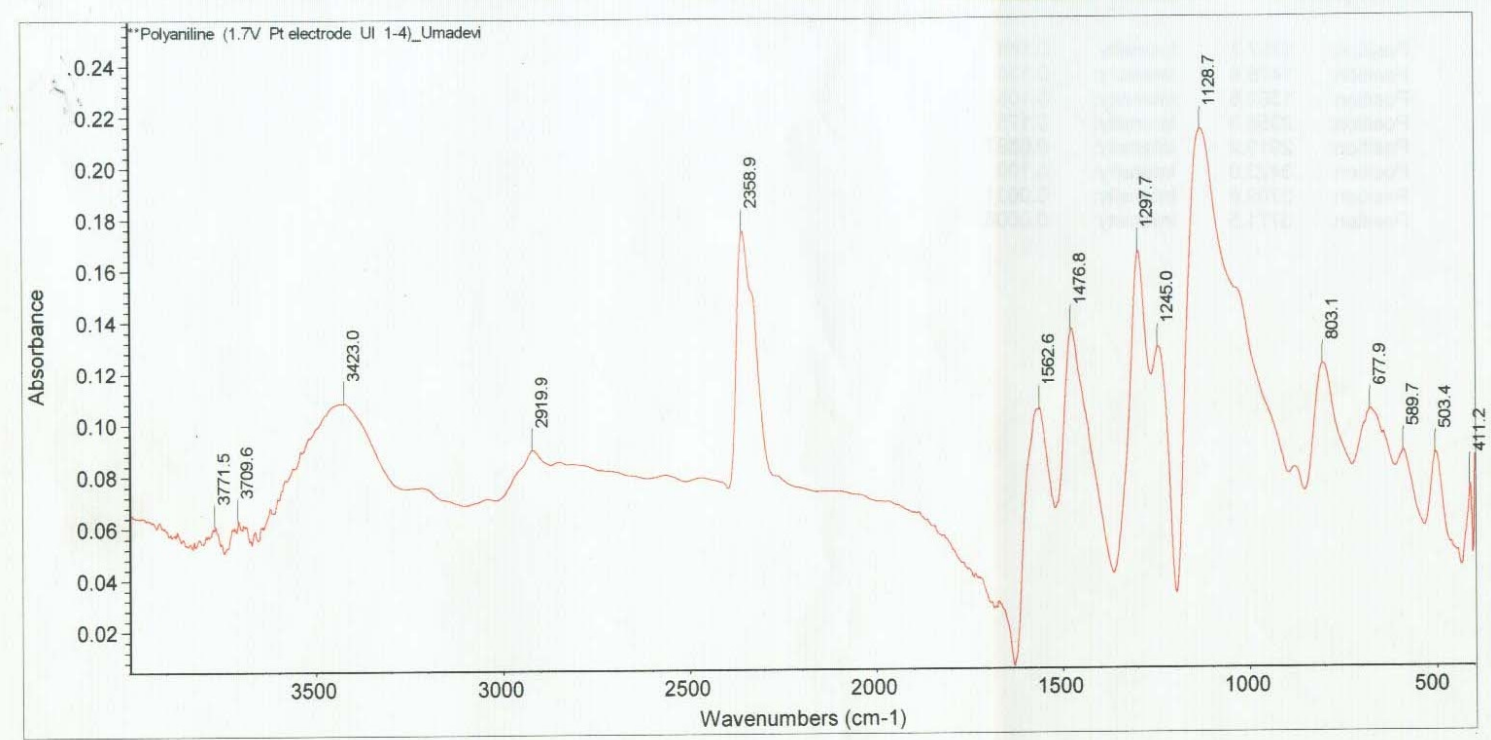

Figure 4. FTIR of polyaniline at $1.7 \mathrm{~V}$ - platinum electrode. 


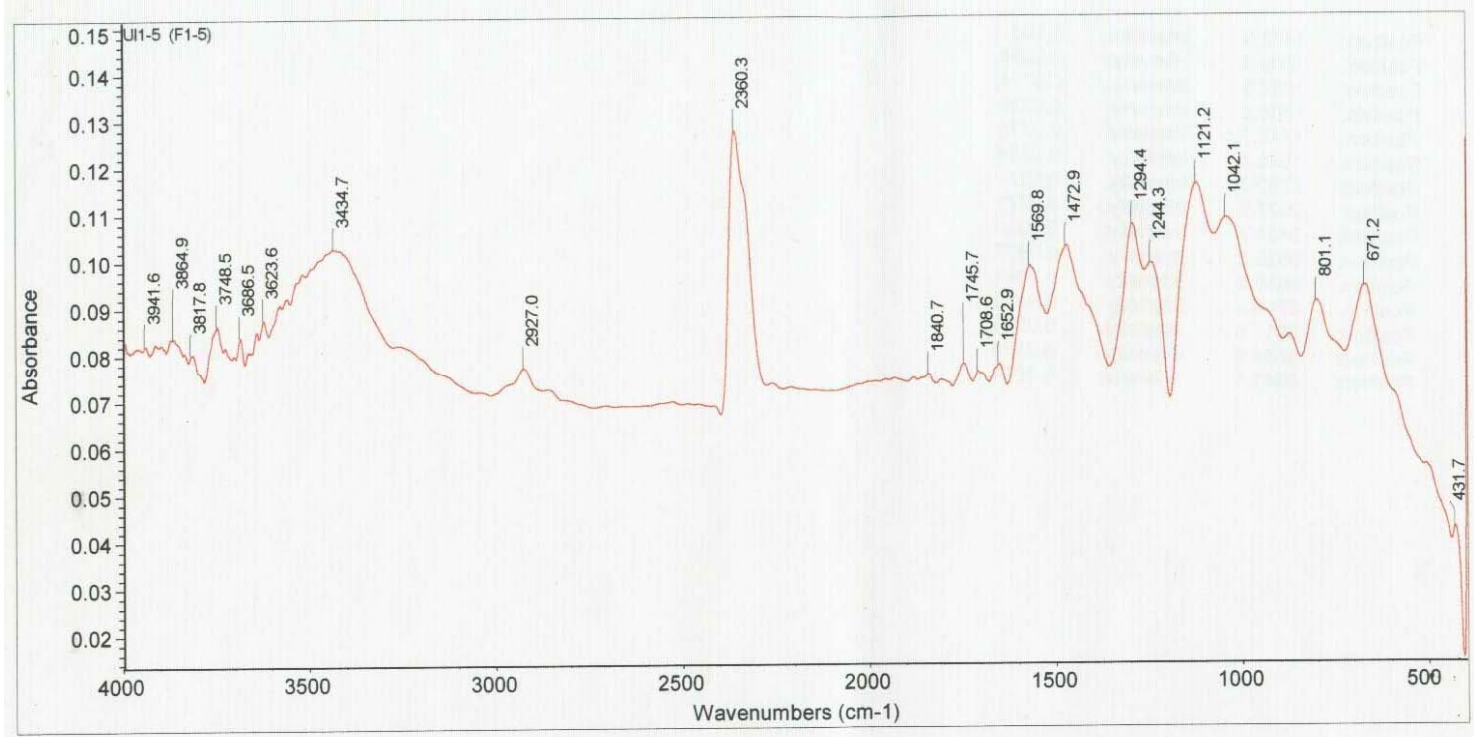

Figure 5. FTIR of polyaniline at $1.9 \mathrm{~V}$ - platinum electrode.

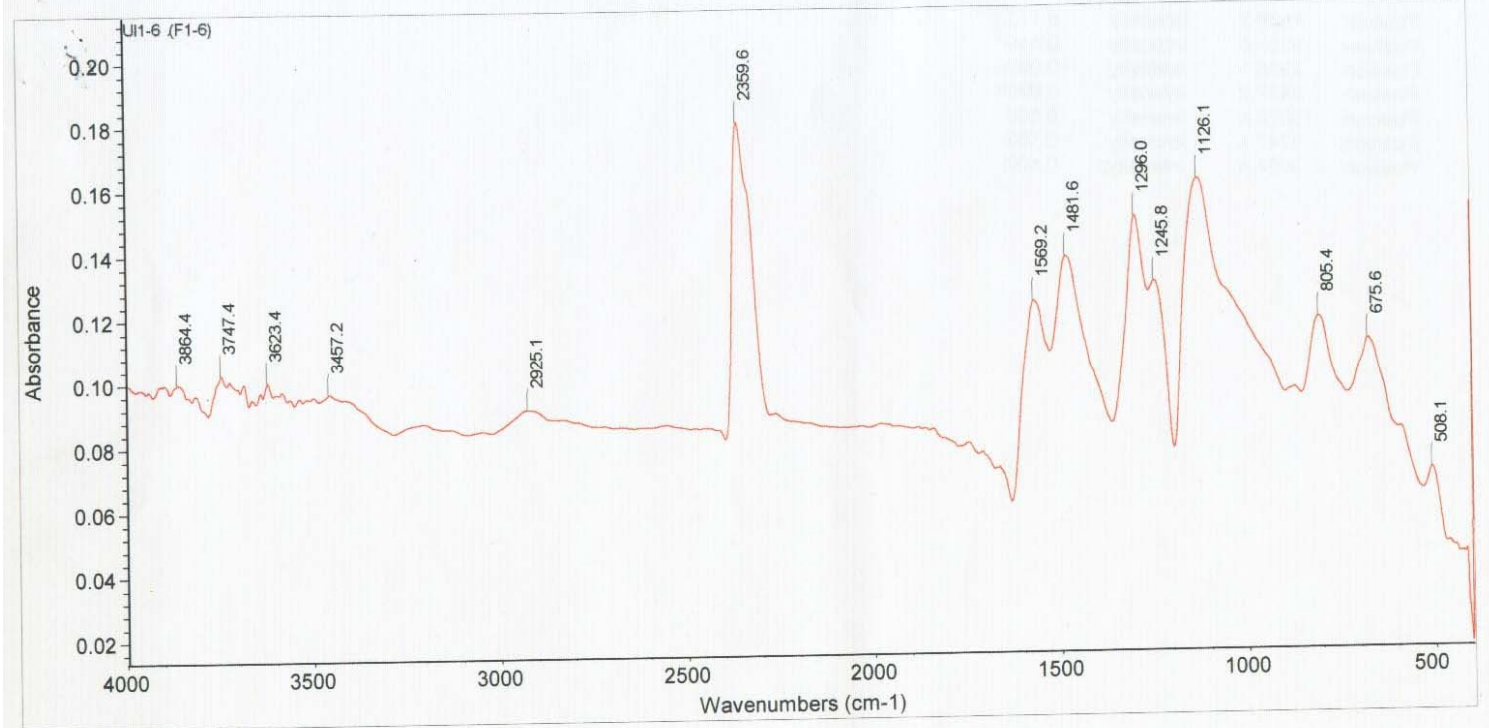

Figure 6. FTIR of polyaniline at $2.1 \mathrm{~V}$ - platinum electrode.

In the case of $\mathrm{HCl}, 1.7 \mathrm{~V}$ is the DC voltage at which PANI conductivity is observed. The conductivity behaviour is exhibited very well in this case.

At $1.1 \mathrm{~V}: \mathrm{N}-\mathrm{H}$ stretching is predominant in this case $: \mathrm{C}=\mathrm{C}$ stretching is predominant in this case

At $1.3 \mathrm{~V}$ : C-N vibration is supported by $\mathrm{HCl}$ PANI

: $\mathrm{C}-\mathrm{H}$ vibration is observed in the presence of $\mathrm{HCl}$

At $1.5 \mathrm{~V}: \mathrm{N}-\mathrm{H}$ stretching is predominant in this case

At $1.7 \mathrm{~V}$ : A strong band at $1130 \mathrm{~cm}^{-1}$ is considered to be the measure of the degree of electron delocalization and thus it is the characteristic peak of PANI conductivity 
At 1.9 V: Quinoid, C-N vibration and, benzenoid structure is supported by $\mathrm{HCl}$ doped PANI

At 2.1 V: C-H vibration is observed in $\mathrm{HCl}$ based PANI.

Quinoid structure exhibited by $\mathrm{HCl}$ PANI at $1.9 \mathrm{~V}$ is exhibited at $1.7 \mathrm{~V}$. The dopant anion on PANI prepared using $\mathrm{HCl}$ would be $\mathrm{Cl}^{-}$anions.

\section{Conclusions}

1. In general, electrochemically synthesized polyaniline gives more pure form of polyaniline than that one chemically synthesized.

2. A strong band at $1130 \mathrm{~cm}^{-1}$ is considered to be the measure of the degree of electron delocalization and thus it is characteristic peak of PANI conductivity.

3. FTIR spectra indicate the presence of polarons and bipolarons in the PANI samples and also stretching, bending modes of vibration which are available in polyaniline.

4. Polyaniline has been synthesized using D.C. voltages ranging from 1.1 to $2.1 \mathrm{~V}$. Among these applied voltages, polyaniline formation has been confirmed at $1.7 \mathrm{~V}$ for $\mathrm{HCl}$.

\section{References}

1. J. Chaing and A.G. MacDiarmid, Synth. Met. 13 (1986) 193.

2. A.F. Diaz and J.A. Logan, J. Electroanal. Chem. III (1980) 114.

3. A.G. MacDiarmid, S.L. Mu et al., Mol. Crys. Liq. Crys. 121 (1985) 187.

4. $\quad$ B.C. Wang, J.S. Tang and F.S. Wang, Synth. Met. 13 (1986) 329.

5. T. Kobayashi, H. Yoneyama and H. Tamura, J. Electroanal. Chem. 177 (1984).

6. E.M. Genies and C. Tsintavis, J. Electroanal. Chem. 195 (1985) 109.

7. A.F. Diaz and J.A. Logan, J. Electroanal. Chem. 111 (1980) 111.

8. M. Nakayama, S. Sacki, K. Ogura, Anal. Sci. 15 (1999) 259.

9. J. Stejskal, A. Riede, D. Hlavata, J. Prokes, M. Helmstedt, P. Holler, Synth. Met. 96 (1998) 55.

10. T. Abdiryim, Z. Xiao-Gang, R. Jamal, Mater. Chem. Phys. 90 (2005) 367. 